\title{
Treating Malignancy: Four-Year Experience in Internal Medicine Department, BIRDEM General Hospital
}

\author{
Sarker RSC ${ }^{a^{*}}$, Rahman $\mathrm{MR}^{\mathrm{b}^{*}}$, Afroze $\mathrm{SR}^{\mathrm{c}}$, Rahim MA ${ }^{\mathrm{d}}$, Uddin $\mathrm{KN}^{\mathrm{e}}$
}

\begin{abstract}
Background: Cancer prevalence in diabetic patients in Bangladesh seems to be increasing as case detection of both diseases are far more than before. Till date no statistical data of diabetic patients with malignancy is available in Bangladesh. Treating both diabetes and malignancy in the same patient is challenging and sometimes requires multidisciplinary support. For such cases BIRDEM General Hospital offers supportive facilities including intensive care, chemotherapy, surgical intervention and oncology day care.
\end{abstract}

Methods: This cross-sectional, observational study was carried out from January 2012 to June 2016 which included cancer patients irrespective of their diabetic status admitted in Internal Medicine Department of BIRDEM General Hospital. With prior informed consent of the patients, data were collected and statistical analysis was done using professional SPSS version 17.0 windows based program.

Results: Total number of cancer patients was 114, whose diagnoses were confirmed by histopathological evidence (biopsy/FNAC), radiology reports and cancer markers, as appropriate. Among them 64 (56.1\%) were male and 50 (43.9\%) were female patients. Age of most of the patients was between 41-60 years (65, $57 \%$ ). Mean age was 55.16 years in diabetic group and 44.47 years in non-diabetic group. Glycemic status revealed that most of the patients were diabetic (80, 70.2\%). Among other co-morbid conditions, hypertension and ischemic heart disease were predominant (17 and 9 cases respectively). Prevalence of more than one comorbidites were marked in the diabetic group (33 cases, $p$ value $>0.001$ ).

Twenty one categories of malignancies were diagnosed during this study period. Majority of cases were lymphoma $(21,18.4 \%)$, carcinoma breast $(17,14.9 \%)$, carcinoma uterus and/or cervix $(13,11.4 \%)$ and leukaemia $(10,8.8 \%)$. Common clinical features included palpable lump $(21,18.4 \%)$, lymphadenopathy $(16,14 \%)$, anaemia $(9,7.9 \%)$ and pain $(8,7 \%)$. The number of patients presenting with multiple signs/symptoms were also significant $(32,28.1 \%)$.

Most patients were treated with chemotherapy (54,47.4\%). Many cases warranted a combined approach (46,40.4\%). Treatment response showed good response in 57(50\%) cases. In 16 patients (14\%) condition deteriorated and death occurred in 8 cases (7\%). Even after repeated and empathic counseling we lost follow up of 15 cases $(13.2 \%)$.

Conclusion: The scenario becomes complicated when a diabetic patient develops malignancy and vice versa. Complications can arise from either spectrum of the diseases. Managing such cases are often challenging and require multi-disciplinary support. Management outcome of these cases so far in Internal Medicine Department, BIRDEM General Hospital shows a promising future.

Key words: BIRDEM; diabetes; experience; malignancy

(BIRDEM Med J 2016; 6(2): 107-111)

\footnotetext{
Author Informations

a. Dr. Rene Suzan Claude Sarker, Senior Medical Officer, Department of Internal Medicine, BIRDEM General Hospital.

b. Dr. Md. Raziur Rahman, Associate Professor, Department of Internal Medicine, BIRDEM General Hospital.

c. Dr. Samira Rahat Afroze, Registrar, Department of Internal Medicine, BIRDEM General Hospital.

d. Dr. Muhammad Abdur Rahim, Assistant Professor, Department of Nephrology, BIRDEM General Hospital.

e. Prof. Khwaja Nazim Uddin, Professor, Department of Internal Medicine, BIRDEM General Hospital.
}

Address of correspondence: Dr. Rene Suzan Claude Sarker, Senior Medical Officer, Department of Internal Medicine, BIRDEM General Hospital. E-mail: renesuzan@gmail.com

*The first two authors had equal contributions and will be considered as first authors.

Received: May 16, 2016

Accepted: May 30, 2016 


\section{Introduction}

As a tertiary care hospital, Bangladesh Institute of Research and Rehabilitation in Diabetes, Endocrine and Metabolic Disorders (BIRDEM) General Hospital is mostly serving diabetic patients with multiple complications. Cancer prevalence in diabetic patients in Bangladesh seems to be increasing as case detection of both diseases are far more than before. No statistical data of diabetic patients with cancer is currently available in Bangladesh. Worldwide, cancer is the second and diabetes is the $12^{\text {th }}$ leading cause of death. ${ }^{1}$

Taking care of diabetes and malignancy in the same patient is challenging. In Bangladesh where advanced treatment facilities are limited, a patient with cancer and uncontrolled diabetes often suffers. Sometimes cancer patients with uncontrolled diabetes are referred to our hospital before any intervention. Vice versa, when a patient with diabetes is detected with malignancy we refer the patient to cancer specialist/cancer hospitals.

To reduce the sufferings of the patients, especially those who require intensive diabetic care, we have started treating cases with cancers in Internal Medicine Department with limited resources and facilities. For such cases BIRDEM General Hospital also offers supportive facilities including intensive care, chemotherapy, surgical intervention and oncology day care.

\section{Methods}

In this cross-sectional, observational study from January 2012 to June 2016, cancer in adult patients irrespective of their diabetic status admitted in Internal Medicine Department of BIRDEM General Hospital were included. With prior informed consent of the patients data was collected and statistical analysis was done using professional SPSS version 17.0 windows based program.

\section{Results}

Total number of cancer patients was 114, whose diagnoses were confirmed by histopathological evidence (biopsy/FNAC), radiology reports and cancer markers. Among them 64 (56.1\%) were male and 50 (43.9\%) were female patients. Most $(80,70.2 \%)$ of the patients were diabetic. Among other co-morbid conditions (Table I), hypertension (HTN) and ischemic heart disease (IHD) were predominant (17 and 9 cases respectively). Prevalence of more than one co- morbidites were marked in the diabetic group (33 cases, $\mathrm{p}$ value $>0.001)$.

Table I. Co-morbid conditions of the patients

\begin{tabular}{lccc}
\multirow{2}{*}{ Co- morbid } & \multicolumn{2}{c}{ Glycemic status } & Total \\
\cline { 2 - 3 } conditions & Diabetic & Non Diabetic & \\
\hline None & 21 & 31 & 52 \\
HTN & 15 & 2 & 17 \\
IHD & 9 & 0 & 9 \\
Liver disease & 2 & 0 & 2 \\
Others & 0 & 1 & 1 \\
More than one & 33 & 0 & 33 \\
\hline Total & 80 & 34 & 114 \\
\hline
\end{tabular}

Age of most of the patients was between 41-60 years $(65,57 \%)$. Others were above $>60$ years $(26,22.8 \%)$ and among 20-40 years group (21, 18.4\%). Mean age was 55.16 years in diabetic group and 44.47 years in non-diabetic group (Table II). If we compare the diabetic and non-diabetic groups, it can be found that relatively younger patients were more in the non-diabetic group (mean age $=44.17$ years) compared to diabetic group (Mean age $=55.16$ years $)$.

Table II. Age group with glycemic status

\begin{tabular}{ccccc}
\multirow{2}{*}{$\begin{array}{l}\text { Age group } \\
\text { (in years) }\end{array}$} & \multicolumn{2}{c}{ Glycemic status } & Total & $\%$ \\
\cline { 2 - 3 } & Diabetic & Non Diabetic & & \\
\hline$<20$ & 0 & 2 & 2 & 1.8 \\
$20-40$ & 7 & 14 & 21 & 18.4 \\
$41-60$ & 51 & 14 & 65 & 57.0 \\
$>60$ & 22 & 4 & 26 & 22.8 \\
\hline Total & 80 & 34 & 114 & 100 \\
\hline
\end{tabular}

Twenty one categories of malignancies were diagnosed during this study period. Majority of cases were lymphoma $(21,18.4 \%)$, carcinoma breast $(17,14.9 \%)$, carcinoma uterus and/or cervix $(13,11.4 \%)$ and leukaemia $(10,8.8 \%)$. In the diabetic group increased prevalence of lymphoma and carcinoma breast were observed (Table III). 


\begin{tabular}{|c|c|c|c|c|}
\hline Table III. Oncolo & $\begin{array}{l}\text { cal diag } \\
\text { status }\end{array}$ & osis with & glyc & \\
\hline Diagnosis & Glycemi & status & & \\
\hline & Diabetic & $\begin{array}{c}\text { Non } \\
\text { Diabetic }\end{array}$ & Total & $\%$ \\
\hline Lymphoma & 16 & 5 & 21 & 18.4 \\
\hline Ca Breast & 11 & 6 & 17 & 14.9 \\
\hline Ca lung & 3 & 3 & 6 & 5.3 \\
\hline Ca Stomach & 4 & 4 & 8 & 7.0 \\
\hline Ca uterus and/or Cervix & 9 & 4 & 13 & 11.4 \\
\hline Multiple myeloma & 4 & 1 & 5 & 4.4 \\
\hline Ca pancreas & 5 & 0 & 5 & 4.4 \\
\hline Ca colon & 0 & 3 & 3 & 2.6 \\
\hline Leukaemia & 5 & 5 & 10 & 8.8 \\
\hline Salivary gland $\mathrm{Ca}$ & 1 & 1 & 2 & 1.8 \\
\hline Ca rectum & 2 & 1 & 3 & 2.6 \\
\hline Multiple metastasis & 5 & 1 & 6 & 5.3 \\
\hline Prostatic Ca & 2 & 0 & 2 & 1.8 \\
\hline Hepatic Ca & 2 & 0 & 2 & 1.8 \\
\hline $\mathrm{Ca}$ GB & 1 & 0 & 1 & 0.9 \\
\hline $\mathrm{RCC}$ & 3 & 0 & 3 & 2.6 \\
\hline $\mathrm{Ca} U \mathrm{~B}$ & 2 & 0 & 2 & 1.8 \\
\hline $\mathrm{CNS} \mathrm{Ca}$ & 1 & 0 & 1 & 0.9 \\
\hline Ca Spinal cord & 1 & 0 & 1 & 0.9 \\
\hline Caoesophagus & 1 & 0 & 1 & 0.9 \\
\hline Primary unknown & 2 & 0 & 2 & 1.8 \\
\hline$\overline{\text { Total }}$ & 80 & 34 & 114 & 100 \\
\hline
\end{tabular}

*Ca means carcinoma

Common clinical features (Table IV) included palpable lump $(21,18.4 \%)$, lymphadenopathy $(16,14 \%)$, anaemia $(9,7.9 \%)$ and pain $(8,7 \%)$. The number of patients presenting with multiple signs/symptoms were also significant $(32,28.1 \%)$.

Case confirmation mostly was done by tissue diagnosis (histopathology) following biopsy (97, 76.3\%) and FNAC $(22,19.3 \%)$. Other modalities included radioimaging, cancer markers etc (Table V). On admission, in diabetic and non-diabetic groups mean haemoglobin was 9.7 and $9.9 \mathrm{gm} / \mathrm{L}$ respectively. Mean erythrocyte sedimentation rate (ESR) was 63.7 and $60.1 \mathrm{~mm}$ in $1^{\text {st }}$ hour in diabetic and non-diabetic group respectively.
Table IV. Clinical features of oncology cases

Frequency Percent \% Valid Percent

No feature

1

0.9

0.9

Lump

21

18.4

18.4

Weight loss

1

0.9

0.9

Anorexia

3

2.6

2.6

Anaemia

9

7.9

7.9

Lymphadenopathy

16

14.0

Cough

2

1.8

1.8

Rectal bleed

4

3.5

3.5

Pain

Jaundice

$\begin{array}{ll}8 & 7.0\end{array}$

7.0

Vomiting

4

3.5

3.5

More than one

2

1.8

1.8

Neurological

32

28.1

28.1

$\begin{array}{llll}\text { Haematuria } & 4 & 3.5 & 3.5\end{array}$

$\begin{array}{llll}\text { Uterine bleed } & 2 & 1.8 & 1.8\end{array}$

\begin{tabular}{llll}
\hline Total & 114 & 100.0 & 100.0 \\
\hline
\end{tabular}

Table V. Methods of confirming diagnosis

Frequency Percent \% Valid Cumulative Percent Percent

\begin{tabular}{lcccc}
\hline FNAC & 22 & 19.3 & 19.3 & 19.3 \\
Biopsy & 87 & 76.3 & 76.3 & 95.6 \\
Tumor marker & 1 & .9 & .9 & 96.5 \\
Cytology & 1 & .9 & .9 & 97.4 \\
Imaging & 3 & 2.6 & 2.6 & 100.0 \\
\hline Total & 114 & 100.0 & 100.0 & \\
\hline
\end{tabular}

The few cases of oncologic emergencies were either admitted with it or later developed the emergency during admission (Table VI). Among those, marrow failure (6, $5.3 \%)$, sepsis $(5,4.4 \%)$ and hypercalcaemia $(4,3.5 \%)$ were common. 


\begin{tabular}{|c|c|c|c|c|}
\hline \multirow{2}{*}{$\begin{array}{l}\text { Oncological } \\
\text { emergency }\end{array}$} & \multicolumn{2}{|c|}{ Glycemic status } & \multirow[t]{2}{*}{ Total } & \multirow[t]{2}{*}{ Percent $\%$} \\
\hline & Diabetic & Non Diabetic & & \\
\hline None & 63 & 28 & 91 & 79.8 \\
\hline Marrow failure & 4 & 2 & 6 & 5.3 \\
\hline Sepsis & 5 & 0 & 5 & 4.4 \\
\hline ICSOL* & 1 & 1 & 2 & 1.8 \\
\hline TLS** & 0 & 1 & 1 & .9 \\
\hline $\begin{array}{l}\text { Spinal Cord } \\
\text { compression }\end{array}$ & 0 & 1 & 1 & .9 \\
\hline SVCO $* * *$ & 1 & 1 & 2 & 1.8 \\
\hline Hypercalcaemia & 4 & 0 & 4 & 3.5 \\
\hline SIADH\# & 2 & 0 & 2 & 1.8 \\
\hline Total & 80 & 34 & 114 & 100.0 \\
\hline
\end{tabular}

* ICSOL: intracranial space occupying lesion

** TLS : tumor lysis syndrome

*** SVCO : superior vena cava obstruction

\# SIADH : syndrome of inappropriate anti diuretic hormone

Most patients were treated with chemotherapy (54, 47.4\%). Many cases warranted a combined approach $(46,40.4 \%)$. Cases such as carcinoma breast, uterine and/or cervical cancers needed surgery and chemotherapy and /or radiotherapy. Surgical removal of tumor (both curative and palliative surgery) were required in 7 cases $(6.1 \%)$. The treatment modalities are shown in Table VII. In all cases multidisciplinary approach were needed.

Table VII. Treatment modalities

\begin{tabular}{lccc} 
& Frequency & Percent & Valid Percent \\
\hline Supportive & 5 & 4.4 & 4.4 \\
Chemotherapy & 54 & 47.4 & 47.4 \\
surgery & 7 & 6.1 & 6.1 \\
Radiotherapy & 2 & 1.8 & 1.8 \\
Combination & 46 & 40.4 & 40.4 \\
\hline Total & 114 & 100.0 & 100.0 \\
\hline
\end{tabular}

Treatment response (Table VIII) among stable cases and non-diabetic group was satisfactory. Patients showed good response in 57(50\%) cases. Good response was categorized by improvement of both clinical, biochemical parameters and cancer markers. In 16 patients (14\%) condition deteriorated and death occurred in 8 cases (7\%). Even after repeated and empathic counseling we lost follow up of 15 cases (13.2\%).
Table VIII. Treatment outcome of the patients

\begin{tabular}{lcccc} 
Outcome & \multicolumn{2}{c}{ Glycemic status } & Total & Percent \% \\
\cline { 2 - 5 } & Diabetic & Non Diabetic & & \\
\hline No response & 12 & 1 & 13 & 11.4 \\
Good response & 37 & 20 & 57 & 50.0 \\
Cured & 4 & 1 & 5 & 4.4 \\
Deterioration & 12 & 4 & 16 & 14.0 \\
Death & 5 & 3 & 8 & 7.0 \\
Lost from follow up & 10 & 5 & 15 \\
13.2 & & & & \\
\hline Total & 80 & 34 & 114 & 100.0 \\
\hline
\end{tabular}

\section{Discussion}

In Bangladesh, according to a large study including 6492 cancer patients in National Institute of Cancer Research and Hospital of Bangladesh, the common cancers in adult males included cancers of lung, lymphatics, larynx, oral cavity and skin, while in adult females breast, cervix, lung, oral cavity, lymphatics and ovarian cancer were common ${ }^{2}$. Also in Bangladesh Cancer Registry Report (2005-2007), most frequent cancer was lung cancer followed by carcinoma cervix and breast ${ }^{3}$.

Our study was a small sample based study to share our experience in the field of oncology. Most of the patients were diabetic as this is a well-known diabetes treating institute. In this study majority suffered from lymphoma in both sexes (both Hodgkin and Non-Hodgkin lymphoma) while in adult female patients carcinoma breast, uterine and/or cervical carcinoma were common.

About $57 \%$ of study sample are within age limit of 41 to 60 years which correlates with Bangladesh Cancer Registry Report that showed maximum number of the cancer patients were in age group between 30-65 years, which is around $66 \% \%^{3}$. Most diabetic patients with complications were of older age. On the other hand a good portion of the non-diabetic group were hospital staffs who were detected early as a case of cancer as they were entitled to hospital facilities and also due to early referral.

Epidemiological findings have shown upto two-fold increases in the risks of cancers of the colorectum, breast, endometrium, kidney (renal cell tumours), liver and pancreas among diabetic patients ${ }^{4}$. In our study, carcinoma (breast, uterus and/or cervix, pancreas, rectum, prostate, renal, urinary bladder), lymphoma and multiple myeloma were found to be predominant in 
diabetic group (table VI). Some risk factors are common to both cancer and diabetes which include age, sex, obesity, physical activity, diet, alcohol, and smoking 5 . So, addressing those risk factors may be of benefit in avoiding occurrence of some malignancies.

Majority of patients presented with different clinical features while asymptomatic cases with incidental cancer diagnosis is quite negligible in this study. Another study showed incidental rate is much higher, (e.g. in endometrial carcinoma) in diabetic patients ${ }^{6}$.

Case diagnosis was done largely based on tissue diagnosis (76.3\%) from histopathology samples of bone marrow aspiration and organ biopsy. Many of the cases were suspected initially by radiological evidence which were later proved by histopathology, eventually a combine approach. Only in 2 cases secondary metastases were detected, the primary origins of which remain undiagnosed.

As most of the patients were admitted as routine cases or through emergency department with diabetes related complications, cases with oncological emergencies were less (only about 20\%). Very few suffered from sepsis, marrow failure or tumerlysis syndrome as a direct consequence of chemotherapy or surgery. There was a significant difference among diabetic and non-diabetic group concerning the incidence of oncology emergency any time ( $21.25 \%$ and $17.6 \%$ respectively). This can be explained by concurrent co-mordities and/or complications occurring in diabetic group rather than the non-diabetic group. There are very few studies relating oncological emergency to diabetes. Study with common oncological emergencies in general population with cancer referred back to past $1994^{7}$.

Few cases (e.g. carcinoma breast) were referred out for radio/brachytherapy after complication of chemotherapy developed .Paliative care including surgery/stenting and chemotherapy were offered to few patients with multiple metastasis.

The combined data of 'cured' and 'patient with good response' is significant (54.4\%). Non-diabetic group showed more positive response to treatment $(61.76 \%)$. Even after active empathic care $14 \%$ patients condition deteriorated and $7 \%$ died. Such outcomes are expected in complicated diabetes with terminal illness ${ }^{8}$.

\section{Conclusion}

The terms 'cancer' as well as 'diabetes' is very wellknown in the general population of our country. Incidence of both the diseases are progressively increasing, affecting life physically, socially, financially and psychologically. People are now more cautious and availability of newer and better investigation tools are unveiling the asymptomatic cases in the community. When a diabetic patient develops malignancy, the situation gets complicated. This group of patients need proper control of their glycaemic profile and specific management of malignancy at the same time. Often multi-disciplinary management is required. BIRDEM General Hospital, as a tertiary institute has a promising role here. Our oncology unit started this journey with small steps looking forward to provide a better future to all patients who are fighting against cancer with or without diabetes mellitus.

\section{Acknowledgement}

We would like to acknowledge Prof. Nazmun Nahar, Director General, BIRDEM General Hospital, for her administrative and continuing logistic support for this oncology unit.

\section{Conflict of interest: None}

\section{References}

1. Lopez AD, Mathers CD, Ezzati M, Jamison DT, Murray CJ: Global and regional burden of disease and risk factors, 2001: systematic analysis of population health data. Lancet 2006; 367: 1747-57.

2. Talukder MH, Jabeen S, Islam MJ, Hussain SMA. Distribution of Cancer Patients at National Institute of Cancer Research and Hospital in 2006. Bangladesh Medical Journal. 2008;37(1):2-5

3. Ref-Cancer Registry Report [Internet]. National Institute of Cancer Research and Hospital 2005-2007 [cited 2013 March 29]. Available from: http://www.ban.searo.who.int/LinkFiles/ Publication_Cancer_registry_report.pdf

4. Grote VA, Becker S, Kaaks R. Diabetes mellitus type 2 - an independent risk factor for cancer? Exp Clin Endocrinol Diabetes. 2010;118:4-8.

5. Edward Giovannucci, MD, SCD, David M. Harlan, MD, Michael C. Archer, MA, PHD, DSC, Richard M. Bergenstal, MD, Susan M. Gapstur, PHD, Laurel A. Habel, PHD et al. Diabetes and Cancer-A consensus report. Diabetes Care. 2010 Jul; 33(7): 1674-85.

6. Liao C, Zhang D, Mungo C, et al. Is diabetes mellitus associated with increased incidence and disease-specific mortality in endometrial cancer? A systematic review and meta-analysis of cohort studies. Gynecol Oncol. 2014 Oct; 135(1): 163-71. doi: 10.1016/j.ygyno.2014.07.095. Epub 2014 Jul 27.

7. Markman M. Common complications and emergencies associated with cancer and its therapy. Cleve Clin J Med 1994; 61: $105-14$

8. Craig J. Currie, PHD, Chris D. Poole, PHD, Sara JenkinsJones, MSC, Edwin A.M. Gale, MD, Jeffrey A. Johnson, PHD and Christopher Ll. Morgan, MSC: Mortality After Incident Cancer in People With and Without Type 2 Diabetes. Diabetes Care 2012 Feb; 35(2): 299-304. 